\title{
Bile leak from the duct of Luschka treated with double-balloon enteroscopy ERCP in a patient with Roux-en-Y gastric bypass
}

Bile leaks after laparoscopic cholecystectomy are usually treated using endoscopic retrograde cholangiopancreatography (ERCP). The presence of complex, surgically altered gastrointestinal anatomy poses a diagnostic and therapeutic challenge to the endoscopic treatment of these lesions. Herein, we present a patient with Roux-en-Y gastric bypass who developed a bile leak after cholecystectomy and underwent endoscopic therapy using double-balloon enteroscopy (DBE) ERCP.

A 59-year-old patient with Roux-en-Y anatomy underwent laparoscopic cholecystectomy with removal of a large and inflamed gallbladder. The patient developed abdominal pain and fever postoperatively. A computed tomography scan was performed and revealed a fluid collection near the gallbladder fossa, which measured $5.2 \times 2.8 \mathrm{~cm}$. A percutaneous drain was placed and the patient was sent to our hospital for further surgical treatment. We performed a DBE ERCP, and cholangiogram through the native papilla revealed a bile leak from the right hepatic duct, consistent with a leak from the duct of Luschka ( $\bullet$ Fig. 1a,b). A double pigtail plastic stent was placed ( $\bullet$ Fig. 1c). The bile drainage from the percutaneous leak resolved over the subsequent 72 hours.

To the best of our knowledge, this is the first case report of successful endoscopic treatment of a bile leak from the duct of Luschka in a patient with Roux-en-Y gastric bypass using DBE ERCP. This case also highlights the possibility of bile leaks occurring distal to the cystic duct stump.

The duct of Luschka is an anomaly that directly connects the hepatic ducts to the gallbladder, draining a portion of the right lobe of the liver $[1,2]$. When accidentally severed, it may cause a bile leak leading to biloma formation [1-3]. In patients with normal upper gastrointestinal anatomy, ERCP with stent placement and/or sphincterotomy is an effective therapy $[2,3]$. Although successful biliary cannulation rates in Roux-en-Y situations are lower, we believe that ERCP using DBE should be attempted first, as shown in this case.

In summary, we have shown that an endoscopic approach using advanced ERCP with a double-balloon enteroscope was effective in treating a postoperative leak in a patient with Roux-en-Y gastric bypass, thus sparing the patient from having to undergo a more invasive surgical intervention.

Endoscopy_UCTN_Code_TTT_1AR_2AK

Competing interests: None

\section{Juan Pablo Gutierrez ${ }^{1,2}$, Ioana B. Smith ${ }^{1}$, C. Mel Wilcox ${ }^{1}$, Klaus Mönkemüller ${ }^{1}$}

Division of Gastroenterology and Hepatology, Basil Hirschowitz Endoscopic Center of Excellence, University of Alabama at Birmingham, Birmingham, USA

${ }^{2}$ Department of Gastroenterology Prof. Henry Cohen, Hospital de Clinicas, Montevideo, Uruguay

\section{References}

1 Neumann H, Fry LC, Malfertheiner P et al. Bile leak from the duct of Luschka. Z Gastroenterol 2010; 48: 256-257

2 Javors BR, Simmons MZ, Wachsberg RH. Cholangiographic demonstration of the cholecystohepatic duct of Luschka. Abdom Imaging 1998; 23: 620-621

3 Donnellan F, Zeb F, Courtney G et al. Successful outcome of sphincterotomy and 7 French pigtail stent insertion in the management of post-cholecystectomy bile leaks. Hepatobiliary Pancreat Dis Int 2009; 8: 309-311

\section{Bibliography}

Dol http://dx.doi.org/

10.1055/s-0033-1344864

Endoscopy 2013; 45: E404

(c) Georg Thieme Verlag KG

Stuttgart · New York

ISSN 0013-726X

\section{Corresponding author}

\section{Klaus Mönkemüller, MD, PhD}

Division of Gastroenterology and Hepatology Basil Hirschowitz Endoscopic Center of Excellence Endoscopy Unit, JT 664

619 19th Street $S$

Birmingham, AL 35249

USA

Fax: +1-205-934-6111

klaus1@uab.edu
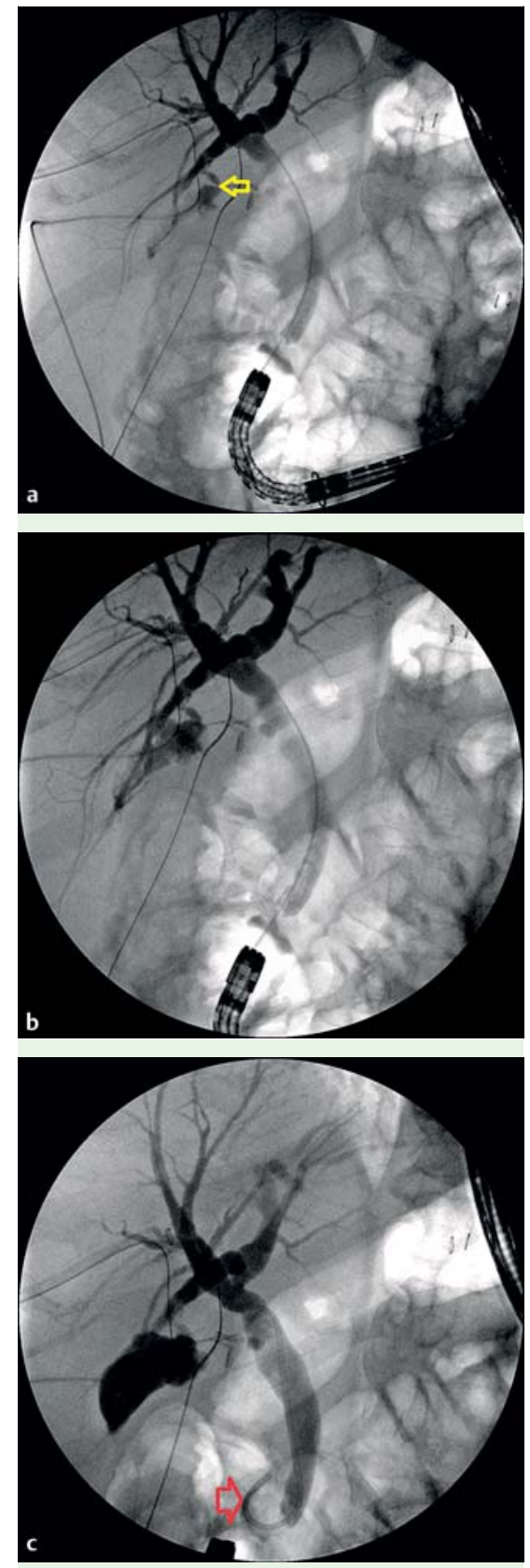

Fig. 1 Cholangiogram through the native papilla. a, b A bile leak was observed from the right hepatic duct, consistent with a leak from the duct of Luschka (yellow arrow). c A double pigtail plastic stent was placed (red arrow). 